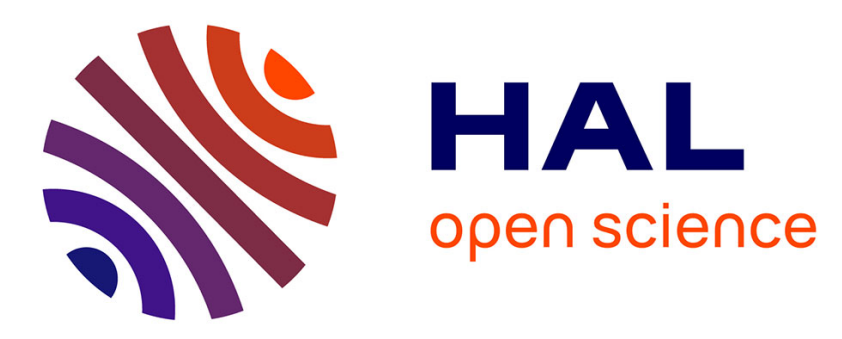

\title{
Study of dispersal as a selection criterion for Trichogrammatidae for biological control in cauliflower greenhouses
}

Elisabeth Tabone, Clément Bardon, Nicolas Desneux

\section{- To cite this version:}

Elisabeth Tabone, Clément Bardon, Nicolas Desneux. Study of dispersal as a selection criterion for Trichogrammatidae for biological control in cauliflower greenhouses. 28th International Horticultural Congress - IHC 2010, Aug 2010, Lisbonne, Portugal. hal-02748595

\section{HAL Id: hal-02748595 \\ https://hal.inrae.fr/hal-02748595}

Submitted on 3 Jun 2020

HAL is a multi-disciplinary open access archive for the deposit and dissemination of scientific research documents, whether they are published or not. The documents may come from teaching and research institutions in France or abroad, or from public or private research centers.
L'archive ouverte pluridisciplinaire HAL, est destinée au dépôt et à la diffusion de documents scientifiques de niveau recherche, publiés ou non, émanant des établissements d'enseignement et de recherche français ou étrangers, des laboratoires publics ou privés. 


\title{
Dispersal study as Trichogrammatidae selection criteria for biological \\ control in cauliflower greenhouses
}

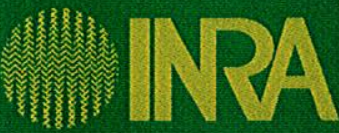

\author{
Bonnet $\mathrm{A}^{1}$, Bardon $\mathrm{C}^{1}$, Desneux $\mathrm{N}^{2}$, Tabone $\mathrm{E}^{1}$
}

IUnité expérimentale Lutte Biologique, INRA, 400 route des chappes, BP 167, 06903 Sophia-Antipolis, France 2Unité de Recherches Intégrées en Horticulture, INRA, 400 route des chappes, BP 167, 06903 Sophia-Antipolis, France

\section{Introduction}

The diamondback moth, Plutella xylostella L. (Lepidoptera: Plutellidae) is the most important pest of cultivated Brassicas worldwide, including several greenhouse plants like cauliflower, cabbage or canola.

The success of inundative biological control programs involving the use of the egg parasitoid Trichogramma wasps (Hymenoptera: Chalcidoidea) to control lepidopterous pests, depended among others, on insect capacity to disperse from introduction points (Smith, 1996)

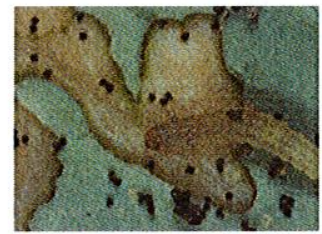

Diamondbackmothl tro

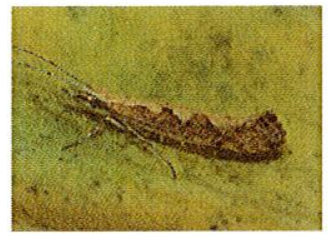

Diamondback mothimago

\section{Objectives}

To control the diamondback moth in cauliflower greenhouses, the dispersal capacity of eight Trichogrammatidae strains (Hymenoptera: Chalcidoidea) was studied with sticky traps in simplified structure of cauliflower crop and in greenhouse. This study permitted to select the Trichogrammatidae the better adapted to cabbage crop environment in greenhouse.

\begin{tabular}{lccc}
\hline \multicolumn{1}{c}{ Species } & Strain & Host & Origin \\
\hline T. bourarachae & Bou-1 & Vanessa cardui & Morocco \\
T. chilonis & Chi-1 & Plutella xylostella & Japan \\
T. chilonis & Chi-2 & Chilo sacchariphagus & Reunion Island \\
T. chilonis & Chi-3 & Ephestia kuelmiella & Taiwan \\
T. evanescens & Eva-1 & Pectinophora gossypiella & Egypt \\
T. evanescens & Eva-2 & Plutella xylostella & France \\
T. ostriniae & Ost-1 & Ephestia kuehniella & Japan \\
T. semblidis & Sem-1 & Plutella xylostella & France \\
\hline
\end{tabular}

Table 1: Host and country of origin of the Trichogramma strains studied

- Sticky traps were green, papers $(7,5 \times 7,5 \mathrm{~cm})$ glued with Tanglefoot 8

- Cauliflower Brassica oleracea botrytis L. Brassicaceae) was used for the experiments as it is the main brassicae cultivated by French seed-bearers. Cabbages were grown in pots in glass insectproof growth chamber $\left(21 \pm 1^{\circ} \mathrm{C}, 60 \pm 5 \% \mathrm{RH}\right.$.)

- Experiments were effected in three parallel glass greenhouses $(4 \times 20 \mathrm{~m})$

Experiment 1: Dispersal in simplified structure of cabbage crop.

Mature cauliflowers in pots were used, placed in cross and $50 \mathrm{~cm}$ spaced (figure 1 left). Sticky traps were placed at canopy level with wood posts at $1 \mathrm{~m}, 3 \mathrm{~m}$ and $5 \mathrm{~m}$ of the release point. Black (i.e. parasited) Ephestia kuehniella eggs stuck on a yellow card were counted, just before Trichogrammatidae emergence, to have thousand females. When more than $50 \%$ of the parasitoids emerged, the tube containing them was placed in a latticed sleeve placed on a cabbage at canopy level (release point)

Number of female trapped was counted at 1,3 and 5 days after the release. Seven repetitions were made for each strain.

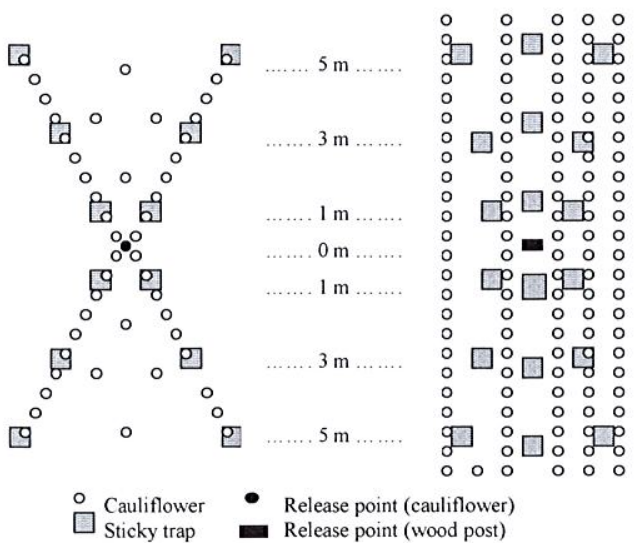

Experiment 2: To follow more precisely the dispersal evolution of trichogramma, we studied the dispersal in real conditions of cabbage crop, but without $P$. xylostella eggs Study started when they measured $5 \mathrm{~cm}$ height. The same protocol that the first

experiment was used, but the number of females trapped was counted everyday during 5 days to better follow dispersal evolution. Six repetitions were made for each strain.

Here, cauliflowers were planted in ground at $20 \mathrm{~cm}$ height and $50 \mathrm{~cm}$ spaced (Fig.1 right).

Statistical:

Percentage of females trapped was calculated for each day and each distance. It was then compared to theorical probability of trap calculated with the hypothesis that Trichogrammatidae fly horizontally and keep a constant speed.

For "y» sticky traps $(7,5 \mathrm{~cm})$ situated to a distance «d»

$$
\text { probability of trap }=\frac{100 \times 7.5 y}{2 \pi d}=\frac{375 y}{\pi d}
$$

where $2 \pi d$ is a circumference of the circle passing by the y points and 7,5 $y$ is the total length of the traps. A dispersal index, weighted mean distance (WMD), was also calculated:

$$
W M D=\frac{n_{1} \times d_{1}+n_{3} \times d_{3}+n_{5} \times d_{5}}{n_{1}+n_{3}+n_{5}}
$$

Where $n$ is the number of females trapped at the distance $d$.

\section{Results}

Dispersal in simplified structure of cabbage crop
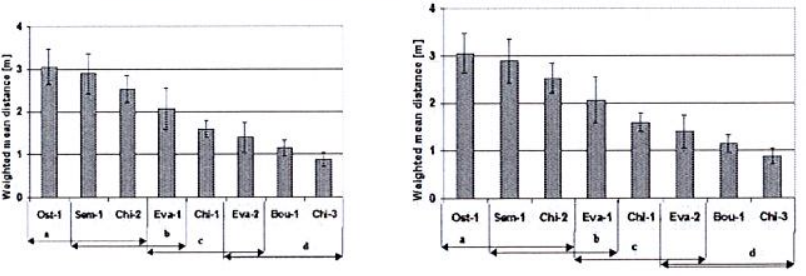

Figure 2. Percentage of females trapped (mean $\pm \mathrm{SE}$ ) same letter means no significative difference, $\mathrm{p}>0,05)$.

- Most important dispersal for

- T. chilonis-2, T. chilonis-1, T. ostriniae-1 and $T$. semblidis- 1

Figure 3. Weighted mean distance (WMD) ( \pm SE) (same letter means no significative difference, $p>0,05$ ).

- T. ostriniae-1, T. semblidis-1, T. chilonis-2 - and T. evanescens-1 had the best dispersal index upper 2 meters

Dispersal in real conditions of cabbage crop

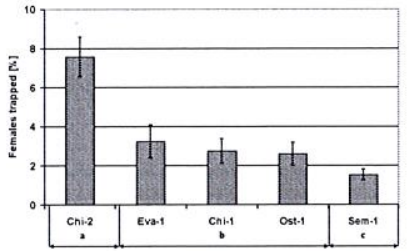

- Trichogrammatidae flow was the mostimportant for $T$. chilonis-2.

- Weighted mean distance did not differ significantly between strains.

Figure 4. Percentage of females trapped (mean \pm SE)

(same letter means no significative difference between strains, $p>0,05)$.

\section{Conclusion}

$T$ chilonis-1, $T$ chilonis-2, $T$ evanescens-1, $T$ ostriniae-1 and $T$. semblidis-1 seemed to be the better adapted to cabbage crop conditions in greenhouse.

Vegetables seem to decrease Trichogrammatidae dispersal by providing increased host searching area, however no eggs were present in our study. These results demonstrate also the importante of working at the strain level rather than at the species level.

Parasitic efficiency of these five strains must to be tested on $P$.xylostella eggs in real conditions of cabbage crop to refine Trichogrammatidae selection for biological control of the diamondback moth. 